\title{
Efforts and success world-wide in the field of clinical pharmacology
}

\author{
A personal review on the occasion of Folke Sjöqvist's 80th birthday
}

\author{
Michael Orme
}

Received: 8 February 2013 / Accepted: 8 February 2013

(C) Springer-Verlag Berlin Heidelberg 2013

\begin{abstract}
In this personal review I describe my early expectations and experiences when I first came to work with Prof. Folke Sjöqvist as a training fellow in the early 1970s. At that time Prof. Sjöqvist and his unit had already earned an international reputation, and in the following decades this success has been magnified many times. Although a description of the research performed by Prof. Sjöqvist during his long career is not the main objective of this article, it is clear that the research carried out in his unit has been instrumental in the development of his international reputation. Over an 18-year period from 1994 onwards, some 272 papers bearing the name of Folke Sjöqvist have been cited over 13,000 times, with an average of over 50 citations per paper. In terms of training clinical pharmacologists from around the world, at the last count 112 individuals from 37 different countries have received a substantial part of their training in his unit. As another measure of his world-wide success, 33 individuals from 18 different countries who received a substantial part of their training in his unit between 1968 and 1996 have gone on to become professors of clinical pharmacology. Prof. Sjöqvist has been requested to consult on various aspects of clinical pharmacology in 15 different countries, from Russia to Spain and from Egypt to Latvia. Here I describe the long-term involvement that Prof. Sjöqvist has had with IUPHAR (now the International Union of Basic and Clinical Pharmacology) and with institutions such as the World Health Organisation (WHO). In particular, I recount his role in the long-term saga involved in updating the original WHO manifesto on clinical pharmacology published in 1970 up to the eventual success of
\end{abstract}

Emeritus Professor, University of Liverpool

M. Orme $(\bowtie)$

Lark House,

Clapton-on-the-Hill, Cheltenham, Gloucestershire GL54 2LG, UK

e-mail: michaelorme@larkhouse.co.uk the new manifesto published by WHO in 2012. Finally, I briefly describe the international honours that have been bestowed on Prof. Sjöqvist, including various prizes, designated lectureships and honorary Doctorates (5). Taken together, these honours provide a magnificent measure of Prof. Sjöqvist's world wide-success-a success that has been emulated by very few clinical pharmacologists.

\section{Introduction}

In the early 1970s, when I became firmly fixed on an academic career in clinical pharmacology, I started to think about how best to extend my training. I had initially trained in internal medicine and had obtained a registrar/senior registrar post in Colin Dollery's (later Sir Colin Dollery) unit at the Royal Postgraduate Medical School. However, all my experience had been in London, with only minor excursions out of the metropolis. I knew that I needed to expand my horizons in order to get a more global perspective of my discipline, and I was keen to work in another country for a year or two. But which country and which unit should I seek to go to?

I had been to the USA and visited some of the clinical pharmacology units there, and I was interested in acquiring the "BTA ('Been to America') diploma". In the end, fate and a much appreciated Wellcome Swedish fellowship took me and the family east in 1973 to Stockholm and the Karolinska Institute where I would work for 18 months in Folke Sjöqvist's unit, then established at Huddinge Hospital in the south of Stockholm. Professor Sjöqvist already had some international experience having trained in clinical pharmacology during 1962 and 1963 at the National Heart Institute in Bethesda USA and at the John Hopkins School of Medicine in Baltimore. During my period of training in Stockholm I was exposed to a steady stream of international scientists from 
many different countries of the world, all of whom had come to talk to Folke Sjöqvist and to take part in some of the work going on in his laboratory. By the time I left, from my very limited perspective, it was clear that Folke already had a substantial international reputation. Now with the experience of 40 years of close collaboration with Folke behind me, I am honoured to have been asked to describe the global impact of Folke's work. I propose to do this by looking from a number of points of view, namely, research, training, administration, development of the discipline and honours received.

\section{Research}

Research has been a major aspect of Folke Sjöqvist's's working life and because of the variety of subject areas and their importance, there are several articles in this publication which do full justice to his endeavour. His work has covered most of the topics that nowadays encompass the whole field of clinical pharmacology. He has been interested in and involved in Therapeutic Drug Monitoring (TDM) from a very early stage of his scientific life. He introduced the concept of TDM into the field of anti-depressant drug therapy based on the finding that polymorphic debrisoquine hydroxylase activity governs the metabolism of several major anti-depressant drugs. This concept has now been incorporated into the clinical care of patients with depression. It is also the cornerstone of the general field of pharmacogenetics, and this approach is becoming increasingly important in the approach to 'personalised drug therapy'. Folke has also been closely involved with setting up rational drug information for prescribers of medicines in an effort to help develop the World Health Organization's (WHO) concept of the rational use of medicines (RUM). His interests have also included pharmacovigilance, pharmacoepidemiology, the development of Drug and Therapeutic Committees and the use and abuse of social medicines, amongst other topics.

All of these subjects have been reported on by Folke and his colleagues in many peer-reviewed publications. He has personally authored more than 500 publications in international journals and his work has been cited very extensively. In a recent citation analysis of 272 papers published between 1994 and the end of 2012, he was cited over 13,000 times (even excluding any self-citations) and the average number of citations per paper was 50.6. Folke's h-index in this analysis was 63. This is clear evidence of a major contribution to the world-wide audience.

\section{Training}

Folke Sjöqvist has always been interested in teaching young people, particularly those who are training to become doctors. He has always been concerned with improving the standard of drug prescribing which is still a problem in every country today. Some of his efforts have been predominantly directed at medical students and doctors in Sweden. (He was chairman of the Curriculum Committee for medical student training at the Karolinska Institute from 1980 to 1987). However, he has been keen to try to improve standards worldwide, either through the writing of textbooks (such as Avery's Drug Therapy ) [1] or through encouraging colleagues to undertake research in the field of education. When I first arrived in Stockholm it was very clear to me that the training of specialist clinical pharmacologists was very high on his agenda. In the 18 months that I was there I had the pleasure of working alongside other trainees from Germany, the Netherlands, the USA as well the UK. A look at Table 1 will illustrate the degree of effort Folke has given to the training of overseas fellows. In this table, I present the number of trainees working at Huddinge over four time periods, namely, the 1970s, the 1980s, the 1990s, and the first decade of the twenty-first century when, although Folke was nominally retired, his influence and presence at Huddinge was still extensive. Overall there have been 112 fellows who trained at Huddinge for a substantial period of time, usually at least 1 year. (I have excluded those individuals who visited Huddinge for a only a short time.). In each decade there were at least 23 fellows trained and in all, 37 countries were represented. All populated continents were represented, with most fellows in the early years coming from the USA and Europe, while in later years the greatest numbers came from Japan, China and African countries. This is an amazing record of involvement that illustrates Folke's worldwide approach to the development of clinical pharmacology.

Another way to look at the worldwide impact that Folke and his unit has had is to look at the number of fellows who trained at Huddinge and who have gone on to become professors of clinical pharmacology. This information is shown in Table 2 and reveals that over a period of nearly 30 years from 1968 to 1996, 33 individual scientists who trained at Huddinge for a substantial period went on to become a full professor of clinical pharmacology.

Eighteen countries are represented by these individuals, and again all populated continents are represented in this list. There can be few scientists who have had such an international impact on their discipline.

\section{Administration}

Folke Sjöqvist was head of his department at Huddinge from 1972 until his retirement in 2001. He was also chief physician and director of research at Huddinge from 1987 to 1997. In terms of international exposure he was a member of the Nobel Assembly and the Nobel Committee in Medicine 
Table 1 Country of origin and timing of non-Swedish fellows who trained at the Karolinska Institute in Stockholm between 1970 and 2010
Numbers in table are the number of non-Swedish fellows at Prof.

Folke Sjöqvist's laboratory. They do not include 33 individuals who came for only a short-term visit/work

${ }^{\mathrm{a}}$ Was then Czechoslovakia

${ }^{\mathrm{b}}$ In the 1970s trainees were from West Germany

\begin{tabular}{llllll}
\hline Country & & & \\
\cline { 2 - 5 } & Time period & & \\
\cline { 2 - 5 } & $1970-1980$ & $1980-1990$ & $1990-2000$ & $2000-2010$ & Total \\
\hline
\end{tabular}

\section{Europe}

Belgium

1

Croatia

Czech Republic $^{\mathrm{a}} \quad 1$

Estonia

Finland

France

Germany $^{b}$

Italy

6

Lithuania

Netherlands

Norway

Russia

Serbia

Spain

UK

3

$\begin{array}{ll}1 & 1 \\ 2 & 1 \\ 1 & 1 \\ & 2 \\ 1 & 2 \\ & 3 \\ & 7 \\ & 4 \\ & 1 \\ 1 & 3 \\ 1 & 1 \\ 1 & 1 \\ 1 & 1 \\ & 8 \\ & 5 \\ & 41\end{array}$

\section{Africa}

Burkino Faso

Ethiopia

Ghana

2

2

3

2

Libya

Nigeria

Somalia

Sudan

Tanzania

Uganda

Zimbabwe

2

$1-1$

2

1

1

1

1

\section{Americas}

Argentina

Canada

Panama

USA

Uruguay

7

1
1
7
2
2
2
1

2

$2-5$

2

110

1

19

Asia

\begin{tabular}{|c|c|c|c|c|c|}
\hline China & & 7 & 5 & 1 & 13 \\
\hline India & 1 & & & & 1 \\
\hline Indonesia & & 1 & & & 1 \\
\hline Japan & & 3 & 3 & 10 & 16 \\
\hline South Korea & & & 1 & & 1 \\
\hline Turkey & & & 1 & & 1 \\
\hline & & & & & 33 \\
\hline \multicolumn{6}{|l|}{ Australasia } \\
\hline Australia & & 1 & & & 1 \\
\hline Totals & 23 & 35 & 25 & 29 & 112 \\
\hline
\end{tabular}


Table 2 Individuals training in clinical pharmacology at the Karolinska Institute between 1968 and 1996 who went on to become professors of clinical pharmacology in their home country

\begin{tabular}{|c|c|c|c|}
\hline Name & Country & Year(s) working at Karolinska Institute & Career position \\
\hline Dan Azarnoff & USA & 1968 & Prof. of Clinical Pharmacology \\
\hline Per Knut Lunde & Norway & 1969 & Prof. of Clinical Pharmacology \\
\hline Sumner Yaffe ${ }^{\mathrm{a}}$ & USA & $1969-1970$ & Prof. of Paediatric Cliniical Pharmacology \\
\hline Marcus Reidenberg & USA & 1970 & Prof. of Clinical Pharmacology \\
\hline Michael Rawlins & UK & $1972-1973$ & Prof. of Clinical Pharmacology \\
\hline Michael Orme & UK & $1973-1974$ & Prof. of Clinical Pharmacology \\
\hline Charles Hoppel & USA & 1973-1974 & Prof. of Clinical Pharmacology \\
\hline Michel Eichelbaum & Germany & 1973-1974 & Prof. of Clinical Pharmacology \\
\hline Chris van Boxtel & Netherlands & $1974-1975$ & Prof. of Clinical Pharmacology \\
\hline John Wilson & USA & 1974-1975 & Prof. of Paediatric Clinical Pharmacology \\
\hline Kamala Krishnaswamy & India & 1977 & Prof. of Clinical Pharmacology \\
\hline Douglas Rollins & USA & $1977-1978$ & Prof. of Clinical Pharmacology \\
\hline Hans Ulrich Schulz & Germany & 1979 & Prof of Clinical Pharmacology \\
\hline Philip Walson & USA & 1979-1980 & Prof. of Paediatric Clinical Pharmacology \\
\hline Lou Yai-Ching & China & 1980 & Prof. of Clinical Pharmacology \\
\hline Francisco Estevez & Uruguay & 1980-1981 & Prof. of Clinical Pharmacology \\
\hline Oladapo Walker & Nigeria & $1981-1982$ & Prof. of Clinical Pharmacology \\
\hline Chiang Wen Teh & China & $1981-1982$ & Prof. of Clinical Pharmacology \\
\hline Dun Ren Pong & China & $1981-1983$ & Prof. of Clinical Pharmacology \\
\hline Don Birkett & Australia & 1982 & Prof. of Clinical Pharmacology \\
\hline Yuichi Koike & Japan & $1982-1984$ & Prof. of Clinical Pharmacology \\
\hline Julio Benitez & Spain & $1983-1984$ & Prof. of Clinical Pharmacology \\
\hline Edoardo Spina & Italy & $1983-1984$ & Prof. of Clinical Pharmacology \\
\hline David Ofori-Adjei & Ghana & 1984-1985 & Prof. of Clinical Pharmacology \\
\hline Paul Mitenko & Canada & 1984 & Prof. of Clinical Pharmacology \\
\hline Ken Woodhouse & UK & $1984-1985$ & Prof. of Geriatric Clinical Pharmacology \\
\hline Tom Perry & Canada & $1986-1987$ & Prof. of Clinical Pharmacology \\
\hline Emilio Sanz & Spain & $1986-1988$ & Prof. of Cinical Pharmacology \\
\hline Adrian Llerena & Spain & 1989-1992 & Prof. of Clinical Pharmacology \\
\hline Gilles Paintaud & France & 1990-1992 & Prof. of Clinical Pharmacology \\
\hline Keun Roh & South Korea & 1993-1995 & Prof. of Clinical Pharmacology \\
\hline Juan Antonio Carillo & Spain & 1994-1996 & Prof. of Clinical Pharmacology \\
\hline MaLuisa Bernal Ruiz & Spain & 1995-1996 & Prof. of Clinical Pharmacology \\
\hline
\end{tabular}

Thirty-three individual medical scientists from 18 different countries who trained at the Karolinska Institute during the period $1968-996$ went on to become professors of clinical pharmacology

${ }^{\mathrm{a}}$ Deceased

from 1972 to 1999 . This then led to him giving the presentation speech to the King of Sweden concerning the winners of the Nobel Prize for Physiology or Medicine in 1988, Sir James Black, Gertrude B. Elion and George H. Hitchings which was transmitted around the world on television.

Folke was often approached for consultation by countries concerned by developments and/or interested in the discipline of clinical pharmacology. He made some 15 visits to different countries, including Egypt, Russia and a number of European countries, such as Croatia, Denmark, Estonia,
Finland, Latvia, Lithuania, Norway, Serbia and Spain. His involvement with Spain through this and other routes, including having training fellows from Spain, has led to major successes in the growth of clinical pharmacology in that country. His work with colleagues in Egypt has led both to new research opportunities as well strong support for the development of the discipline of clinical pharmacology in Egypt. In addition, in 1979-1980 he returned to the USA as a special assistant to the director of the National Institute of General Medical Sciences and, among other activities, he was 
closely involved in discussions about the development of clinical pharmacology in the USA.

\section{Development of the discipline of clinical pharmacology}

In one sense the above-mentioned international consultations also focused on efforts to develop the discipline of clinical pharmacology, but this part of the story goes back to the early 1970s. Folke was part of the working group brought together by the WHO to define the nature and work of clinical pharmacology. The result of this collaboration was the publication of the manifesto on the discipline in 1970 [2]. This document stood the test of time as an advisory document very well throughout the next decade and into the 1980s, but by the mid-1980s it was becoming clear that it very much needed updating. Attempts were made to persuade the WHO in Geneva to convene another working party but without success. The emphasis then changed to Europe and through WHO Europe a number of documents were produced to try to develop the discipline in Europe. The first was a general paper on the overall value of the discipline to healthcare [3], and this was followed by a paper on the teaching and organisation of the discipline [4] and also by a paper on the importance of clinical pharmacology in primary healthcare [5]. Finally, there was an overall summary document [6]. These efforts however still failed to convince the WHO headquarters that there should be a document addressed to the global issues.

In view of the relative success of the European initiative and to fulfil an unmet need, Folke led a few close European colleagues into founding the European Association for Clinical Pharmacology and Therapeutics (EACPT). Following discussions with clinical pharmacologists across Europe, a small working party was formed which brought together colleagues for a small meeting in 1993 in Verona. Folke was then elected the chairman of the interim committee, which was charged with organising the first Congress of EACPT in Paris in 1995. At this congress, which attracted over 1,000 delegates, Folke was elected the first chairman of the executive committee, a position he held for the first four years until 1999.

At the same time Folke was becoming increasingly involved with global matters through the International Union of Pharmacology (IUPHAR), as it was then called. This organisation represents the interests of scientists in pharmacology-related fields worldwide, and in 1996 he was elected chairman of the division of clinical pharmacology within IUPHAR. Folke took a robust interest in this organisation, and in 2000 he was reelected chairman of the clinical division for a further 4-year term. One of his concerns was that the executive committee of IUPHAR was not as involved in clinical matters as he felt it should be. He therefore suggested that the name of IUPHAR be changed to "the International Union of Basic and Clinical
Pharmacology" while keeping the same acronym. After extensive discussions this was agreed to by the executive committee of IUPHAR in 2003, and this decision was ratified by an overwhelming majority of members at the General Assembly of IUPHAR in Beijing in 2006. His links with IUPHAR continue to the present time since he is chairman of the scientific liaison group set up to foster links between IUPHAR and WHO in Geneva.

\section{The new manifesto}

The attempts to revise the original WHO manifesto [2] continued into the first decade of the twenty-first century withat least initially - no success despite the many efforts by Folke. It was then suggested that the original 1970 document be revised anyway in the hope that WHO would come on board. It was Folke's enthusiasm and energy that got this project started, and I joined him in this effort to produce and edit this document. Our target was to produce the new document in time for circulation to all delegates attending the 'World Pharma' congress in 2010 organised by Kim Brosen and his colleagues in Copenhagen. Together with 11 colleagues drawn from a worldwide list of distinguished clinical pharmacologists, the document entitled "Clinical Pharmacology in Research, Teaching and Health Care" was born and delivered on time [7]. It received the backing of IUPHAR and elicited a fair amount of interest and praise from the delegates to the congress as well as from readers of the publication.

Following this meeting in Copenhagen the discussions with WHO were once again initiated with the aim of producing a global document. The talks were joined by Gunilla

Table 3 Some of the international honours bestowed on Professor Folke Sjöqvist 1971-2009

1971 Anna Monica prize for research on Depression-University of Basel 1976 Paul Martini Medal in Clinical Pharmacology-University of Bonn 1977-79 University medals from the universities of Oslo, Helsinki, Turku, London, Cornell, and Amsterdam.

1982 onwards Honorary Doctorate degrees at Universities in:

France ( Besancon)

Finland (Turku)

Estonia (Tartu)

England (Newcastle)

Denmark (Southern Denmark)

1986 Sir Henry Dale lecturer, John Hopkins Medical School

1989 Elected member of Academicae Europeae

1996 Oscar B. Hunter Award from American Society of Clinical

Pharmacology \& Therapeutics (first non-American)

2009 Lifetime achievement award from EACPT

EACPT, European Association for Clinical Pharmacology and Therapeutics 
Sjölin-Forsberg, the secretary general of the Council for International Organizations of Medical Sciences (CIOMS) which, like WHO, is based in Geneva. It quickly became apparent that the organisations were supportive of the venture but that some changes would be needed to produce a document covering worldwide interests. Firstly, three additional chapters, covering the fields of paediatric clinical pharmacology, geriatric clinical pharmacology and traditional medicines, were agreed upon and written. Secondly, an additional editor became involved. Donald Birkett from Australia, as the current chairman of the clinical division of IUPHAR, became closely involved to ensure collaboration with IUPHAR.

Following initial editing, the document was distributed through the WHO system to WHO representatives, clinical pharmacologists and other interested parties for their comments. This process took almost 1 year to complete. We had the benefit of two extra editors and in addition to Gunilla SjölinForsberg (on behalf of CIOMS) we were joined by Lembit Rago (representing WHO). Many suggestions arose from the consultative process, and most of these were incorporated into the final document. In particular, there was a widespread feeling that the document should place more emphasis on healthcare, and as a result the title of the new document was slightly changed, becoming "Clinical Pharmacology in Health Care, Teaching and Research" [8]. The discussions proved fruitful, although the most difficult topic to sort out was the definition of the descriptor "Clinical Pharmacologist". Defining "Clinical pharmacology" proved to be a relatively easy task, but the person descriptor took much discussion before a description emerged that satisfied nearly all parties.

Once approval from WHO and CIOMS was achieved towards the end of 2011 and all of the authors had made any last minute changes to their documents, the editing process began in earnest and was spread over the next 6 months. Thanks to the Email system, messages were flying across the ether several times each week between Australia, Sweden and the UK until, after a short intensive effort in Stockholm in early May 2012, the final document received approval from the Executive Committee of IUPHAR in late May. Shortly thereafter approval by WHO and CIOMS led to publication of the document on the Internet by CIOMS in October 2012 and by WHO in November 2012. Although the document was being distributed worldwide through the Internet we felt it was important to produce a good number of hard copies. We were fortunate to receive financial support for this from the British Pharmacological Society and the Swedish Foundation for Clinical Pharmacology and Pharmacotherapy as well as from CIOMS, IUPHAR and WHO.

\section{Honours}

Having brought the story up to date it is important now to look at the recognition which Prof. Folke Sjöqvist has received around the world in order to judge the global impact his work has produced. Table 3 shows some of the honours and distinctions which he has received. International recognition came relatively early, with prizes and medals in the 1970s, although it was not until the next decade that Folke started to receive more major awards. He has received honorary doctorates from universities in Denmark, Estonia, Finland, France and UK, and he has also been elected as a fellow of the Royal College of Physicians in London.

In 1986 he delivered the Sir Henry Dale lecture at the John Hopkins Medical School in Baltimore (USA) and in 1996 he was given the Oscar B. Hunter Award from the American Society of Clinical Pharmacology and Therapeutics, the first non-American individual to receive that honour. $\mathrm{He}$ is an honorary member of a number of pharmacological societies in Europe, and in 2009 the EACPT awarded Folke the first EACPT Lifetime achievement award for his work throughout Europe for many years.

\section{What of the future?}

The international reputation of the clinical pharmacology unit at the Karolinska Institute is now well assured, and the skill and energy of the current team will ensure a continuation and expansion of that reputation. The manifesto [8] published last year points the way ahead for the discipline of clinical pharmacology over the next decade, particularly in increasing the role of the discipline in healthcare.

One area that the work of Prof. Folke Sjöqvist and his team will see developing is what is becoming known as the field of 'personalised medicine'. Developments in pharmacogenetics and pharmacogenomics will enable individual variation in the response to drugs to be predicted in advance by simple genetic tests. This should enable medicines to be given more effectively and with a lower prevalence of adverse reactions. Hopefully Prof. Folke Sjöqvist will see many more examples of these developments coming to fruition in his lifetime.

Conflict of interest None.

\section{References}

1. Sjöqvist F, Borga O, Dahl M-L, Orme M (1997) Fundamentals of clinical pharmacology (chapter 1). In: Speight TM, Holford NH (eds) Avery's drug therapy, 4th edn. Wiley-Blackwell, Hoboken, pp 1-74

2. World Health Organization (WHO) Study Group (1970) Clinical pharmacology. scope, organisation, training. World Health Org Tech Rep Ser 446:5-21

3. Bircher J, Bogaert M, Dukes MNG, Eichelbaum M, Gram L, Huller H, Orme M, Sjöqvist F, Tognoni G (1988) Clinical pharmacology in 
Europe: an indispensible part of the health service. Eur J Clin Pharmacol 33:535-539

4. Bircher J, Bogaert M, Dukes MNG, Eichelbaum M, Gram L, Huller H, Lunde I, Orme M, Sjöqvist F, Tognoni G (1990) The teaching and organisation of clinical pharmacology in Europe. Eur J Clin Pharmacol 38:101-105

5. Dukes MNG, Lunge PKM, Melander A, Orme M, Sjöqvist F, Tognoni G, Wesseling H (1990) Clinical pharmacology and primary health care in Europe: a gap to bridge. Eur J Clin Pharmacol 38:315-318

6. World Health Organization (1992) Clinical pharmacology: the European challenge. European Series 1991; no 39. WHO Regional Office for Europe, Copenhagen
7. Orme M, Sjöqvist F, Birkett D, Brosen K, Cascorbi I, Gustafsson L, Maxwell S, Rago L, Rawlins M, Reidenberg M, Smith A, Thuerman P, Walubo A (2010) Clinical pharmacology in research, teaching and health care: considerations by IUPHAR, the International Union of Basic and Clinical Pharmacology. Basic Clin Pharmacol Toxicol 107:531-559

8. Orme M, Sjöqvist F, Birkett D, Rago L, Sjolin-Forsberg G (eds) Abernethy D, Brosen K, Cascorbi I, Gustafsson L, Hoppu K, Maxwell S, Rawlins M, Reidenberg M, Smith A, Thuerman P, Walubo A (2012) Clinical pharmacology in health care, teaching and research. WHO/IUPHAR/CIOMS, Geneva. Available at: http:// www.who.int/medicines/areas/quality_safety/safety_efficacy/saf_ pub/en/index.html. Accessed 18 Jan 2013 